\title{
Malignant tumors of the maxillary sinus: Prognostic impact of neurovascular invasion in a series of 138 patients
}

\author{
Marco Ferrari ${ }^{\mathrm{a}, \mathrm{b}, *}$, Alessandro Ioppi ${ }^{\mathrm{a}, \mathrm{c}}$, Alberto Schreiber ${ }^{\mathrm{a}}$, Tommaso Gualtieri ${ }^{\mathrm{a}}$, \\ Davide Mattavelli ${ }^{\mathrm{a}}$, Vittorio Rampinelli ${ }^{\mathrm{a}}$, Stefano Taboni ${ }^{\mathrm{a}}$, Michele Tomasoni ${ }^{\mathrm{a}}$, Paolo Bossi ${ }^{\mathrm{d}}$, \\ Alberto Deganello ${ }^{\mathrm{a}}$, Piero Nicolai ${ }^{\mathrm{b}}$ \\ ${ }^{\mathrm{a}}$ Unit of Otorhinolaryngology - Head and Neck Surgery, Department of Medical and Surgical Specialties, Radiological Sciences, and Public Health, University of Brescia, \\ Brescia, Italy \\ ${ }^{\mathrm{b}}$ Section of Otorhinolaryngology - Head and Neck Surgery, Department of Neurosciences, University of Padua, Padua, Italy \\ ${ }^{\mathrm{c}}$ Unit of Otorhinolaryngology - Head and Neck Surgery, University of Genoa, Genoa, Italy \\ ${ }^{\mathrm{d}}$ Medical Oncology Unit, Department of Medical and Surgical Specialties, Radiological Sciences, and Public Health, University of Brescia, Brescia, Italy
}

\section{A B S T R A C T}

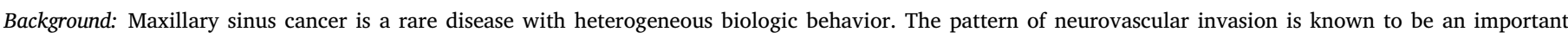
prognosticator in head and neck cancers, but has not been studied in maxillary malignancies.

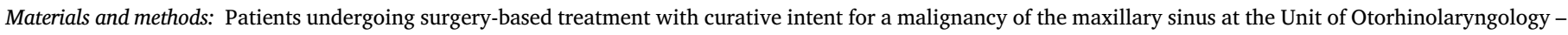

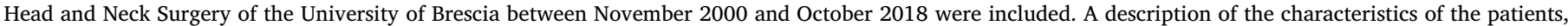

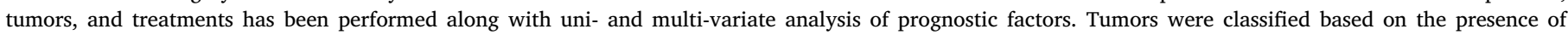
perineural $\left(\mathrm{P}_{0} / \mathrm{P}_{1}\right)$ and lymphovascular invasion $\left(\mathrm{V}_{0} / \mathrm{V}_{1}\right)$ in 4 categories: $\mathrm{P}_{0} \mathrm{~V}_{0}, \mathrm{P}_{1} \mathrm{~V}_{0}, \mathrm{P}_{0} \mathrm{~V}_{1}$, and $\mathrm{P}_{1} \mathrm{~V}_{1}$.

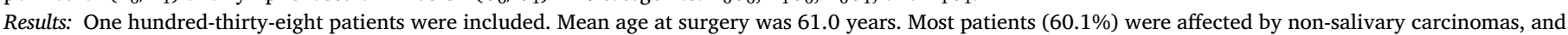

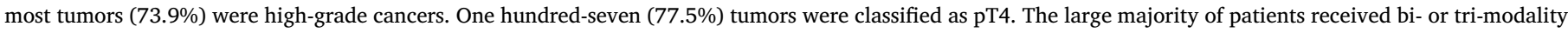

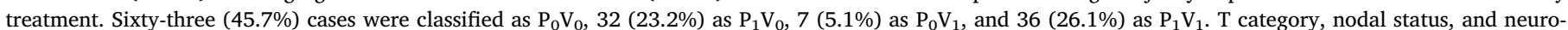

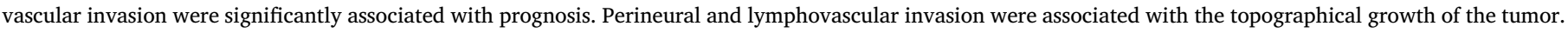

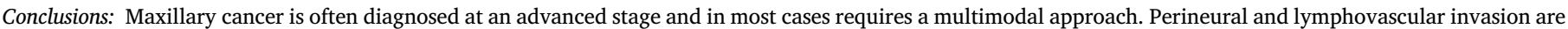
frequent and have a different impact on prognosis and topographical extension of the tumor.

\section{Introduction}

Maxillary sinus cancer is a relatively rare entity that poses several challenges to head and neck (HN) physicians. The site of origin has the peculiarity of limiting early diagnosis while facilitating silent involvement of critical structures. From a prognostic perspective, this translates into late diagnosis and poor outcomes [1-3]. The currently available literature on maxillary cancer is mostly based on single-histology series including squamous cell carcinoma (SCC) and adenoid cystic carcinoma (ACC) [4-10], with little reported on other histologies [1]. This somehow conflicts with the well-settled knowledge that histology substantially affects behavior of sinonasal tumors [11,12].

To date, surgery still represents the cornerstone in the management of maxillary cancer, being the upfront step in most cases. The ablative phase consists of maxillectomy, which can be tailored according to tumor extension. During assessment of tumor margins and osteotomy planning, endoscopy and surgical navigation, respectively, can aid the surgeon in achieving a resection with free margins [13-15]. With the infrequent exception of early cancers which are radically excised, treatment also includes adjuvant radiation $[16,17]$. Moreover, chemotherapy can be used in combination with radiotherapy and/or in the induction setting to modulate the treatment schedule, facilitate orbit preservation and/or improve oncologic results [18-21]. Particle therapy, due to the possibility of better shaping the distribution of radiation doses, has been proposed as an attractive option for advanced maxillary cancers $[22,23]$.

Over the last 3 decades, the evolution of the indications for endoscopic surgery for sinonasal malignancies has focused interest towards nasoethmoidal tumors, which are more frequently amenable to transnasal endoscopic resection. On the contrary, maxillary sinus cancers are rarely manageable with a purely endoscopic approach and have consequently raised less attention in the contemporary literature. Even if

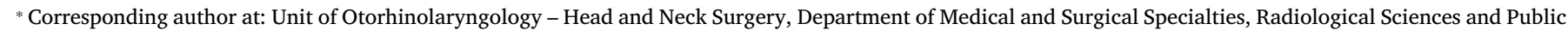
Health, University of Brescia, Piazzale Spedali Civili 1, 25123 Brescia, Italy.

E-mail address: 1990marcoferrari@gmail.com (M. Ferrari). 
multimodal treatment schedules have improved survival rates [8], 5year overall survival (OS) of patients treated for maxillary cancer still ranges between $30.0 \%$ and $62.0 \%$ [2,24-27], with a number of factors affecting prognosis including local and regional extension, tumor grade, margin involvement, perineural invasion (PNI), and lymphovascular invasion (LVI) [2,28-30]. These data suggest that maxillary sinus cancer still represents a field within HN oncology that deserves to be better understood and explored.

The ways that tumors of the HN tend to invade surrounding tissues through nerves and vessels has raised particular interest, especially in view of the fact that cancers exhibiting PNI and/or LVI are associated with poor outcomes (with special reference to ACC) [18,31-37]. Moreover, the pattern of neural and vascular invasion is known to be associated with histology, as different sinonasal cancers display PNI and LVI with heterogeneous frequency [38].

The present study analyzed oncologic data on a series of patients with cancers of the maxillary sinus treated over an 18-year period, under the hypothesis that PNI and LVI significantly affected the pattern of local extension along with the probability and pattern of recurrence.

\section{Materials and methods}

The institutional database of patients receiving surgery for sinonasal cancer at the Unit of Otorhinolaryngology - HN Surgery of the University of Brescia was retrospectively analyzed. Patients who underwent surgery-based treatment with curative intent for maxillary sinus malignancies between November 2000 and October 2018 were included in the study. Patients undergoing palliative surgery, affected by benign neoplasms, or tumors originating from nasoethmoidal complex, oral cavity, hard palate, or orbit were excluded. Indication to maxillectomy was given in keeping with general principles of oncologic HN surgery [3]. Tumors with critical posterior and/or superior extension towards the skull base were managed as described by Deganello et al. [14]. The present study was approved by the local ethics board (protocol number: NP3616).

\section{Demographics, oncologic, and pathologic information}

Information on demographics (gender, age at surgery), tumor characteristics (histology, grade, anatomical extent), previous treatment(s), surgery, and adjuvant therapy were retrieved. Histological nomenclature and classification were adapted to the 4th edition of the "WHO classification of HN tumors" [39]. Margin status, presence of PNI and/or LVI, and local, regional, and distant extension of the tumor were re-classified according to the 8th edition of the "TNM classification of malignant tumors" [40]. Margins were primarily evaluated on the main surgical specimen. When an additional specimen was uninvolved and orientable as additional resection with respect to a positive margin on the main surgical specimen, that margin was considered as clear. Otherwise, if a positive margin was detected on the main specimen with additional specimens being infiltrated and/or non-orientable, the margin status was precautionary defined as involved. PNI was defined as the presence of tumor cells within the perineural space [41]. Invasion of the epineurium with no extension within the perineural space was not sufficient to be classified as PNI. Intraneural invasion was diagnosed when tumor cells were intermingled with neural fibers. LVI was defined if tumors cells were found within vascular wall and/or lumen.

Poorly differentiated SCC, high-grade mesenchymal malignancies, ACC exhibiting a solid component [42], and other tumors indicated as high-grade according to the 4th edition of the "WHO classification of HN tumors" criteria were grouped under the term "high-grade tumors" [39]. Well- and moderately-differentiated SCC, low-grade mesenchymal malignancies, and ACC without a solid component were grouped under the term "low-grade tumors".
Areas and structures surrounding the maxillary sinus were divided in 33 anatomical subunits (Supplementary Table 1). Each anatomical subunit was defined as invaded or non-invaded by the tumor based on systematic analysis of the final histologic description, surgical report, and preoperative imaging, following this hierarchical order. The frequency of invasion of each subunit was assessed.

Each tumor was attributed to one of the following 4 groups: $\mathrm{P}_{0} \mathrm{~V}_{0}-$ tumors with neither PNI nor LVI; $\mathrm{P}_{1} \mathrm{~V}_{0}$ - tumors with PNI alone; $\mathrm{P}_{0} \mathrm{~V}_{1}-$ tumors with LVI alone; $\mathrm{P}_{1} \mathrm{~V}_{1}$ - tumors with both PNI and LVI. This categorization was defined as "pattern of neurovascular invasion". Distribution of histologies within the 4 patterns of neurovascular invasion was assessed.

\section{Statistical analysis}

Descriptive statistics were used for each variable assessed. The association of pattern of neurovascular invasion with histology, grade, and margin status were analyzed with Chi-square test or Fisher's exact test, as appropriate. The associations between pattern of neurovascular invasion and involvement of anatomical structures and areas surrounding the maxillary sinus were studied with the same method. The isolated effect of PNI and LVI on involvement of anatomical structures was tested through a sub-analysis of $\mathrm{P}_{1} \mathrm{~V}_{0}$ versus $\mathrm{P}_{0} \mathrm{~V}_{0}$ tumors and $\mathrm{P}_{0} \mathrm{~V}_{1}$ versus $\mathrm{P}_{0} \mathrm{~V}_{0}$ tumors, respectively. Rates of nodal involvement in low versus high grade tumors and within different histological groups were compared with Chi-square test or Fisher's exact test, as appropriate.

Follow-up duration and patient status at last evaluation were analyzed. Overall (OS), disease-specific (DSS), recurrence-free (RFS), local recurrence-free (LRFS), regional recurrence-free (RRFS), and distant recurrence-free (DRFS) survivals were evaluated with the Kaplan-Meier method. Age at surgery, gender, presentation (i.e. primary vs recurrence), pT category (i.e. pT4 vs pT1-T3), presence of nodal metastases (i.e. $\mathrm{pN}+\mathrm{vs} \mathrm{N} 0$ ), histological category (i.e. non-salivary carcinomas vs salivary carcinomas vs mesenchymal tumors vs neuroectodermal tumors), grading (i.e. high-grade vs low-grade), PNI, LVI, pattern of neurovascular invasion (i.e. $\mathrm{P}_{0} \mathrm{~V}_{0}$ vs $\mathrm{P}_{1} \mathrm{~V}_{0}$ vs $\mathrm{P}_{0} \mathrm{~V}_{1}$ vs $\mathrm{P}_{1} \mathrm{~V}_{1}$ ), margin status (involved margins vs uninvolved margins, and involved margins vs margins $<5 \mathrm{~mm}$ vs $>5 \mathrm{~mm}$ ), and treatment schedule (tested in 3 ways as follows: comparing the 8 clusters showed in Fig. 1, considering patients receiving vs those not receiving induction chemotherapy, comparing patients who received a radical resection vs those with involved margins receiving adjuvant (chemo)radiation vs those with involved margins not receiving adjuvant (chemo)radiation) were tested as prognosticators with univariate survival analysis based on the log rank Mantel-Cox test. A multivariate Cox proportional hazard model test was run to identify independent prognosticators among factors with significance at univariate analysis. Level of significance was set at 0.05 for all statistical tests. P-values within the interval $0.05-0.10$ were defined as close-to-significant.

\section{Results}

\section{Demographics, oncologic, and pathologic information}

One hundred-thirty-eight patients were included in the study. Mean age at surgery was 61.0 years and male-to-female ratio was 1:1. Fortyeight $(34.8 \%)$ patients presented with a recurrent tumor. Eighty-three $(60.1 \%)$ patients were affected by non-salivary carcinomas, mainly represented by SCC. Less frequent histologies were salivary gland carcinomas $(19.6 \%)$, mesenchymal tumors $(13.8 \%)$, and neuroectodermal tumors $(6.5 \%)$ (Table 1$)$. Most tumors (102; 73.9\%) belonged to the high-grade group.

The majority of patients were diagnosed with a high-stage (III or IV) tumor (127 patients; 92.0\%). One hundred-seven (77.5\%) tumors were classified as pT4, 58 of which (42.0\%) were pT4b. Resection included 


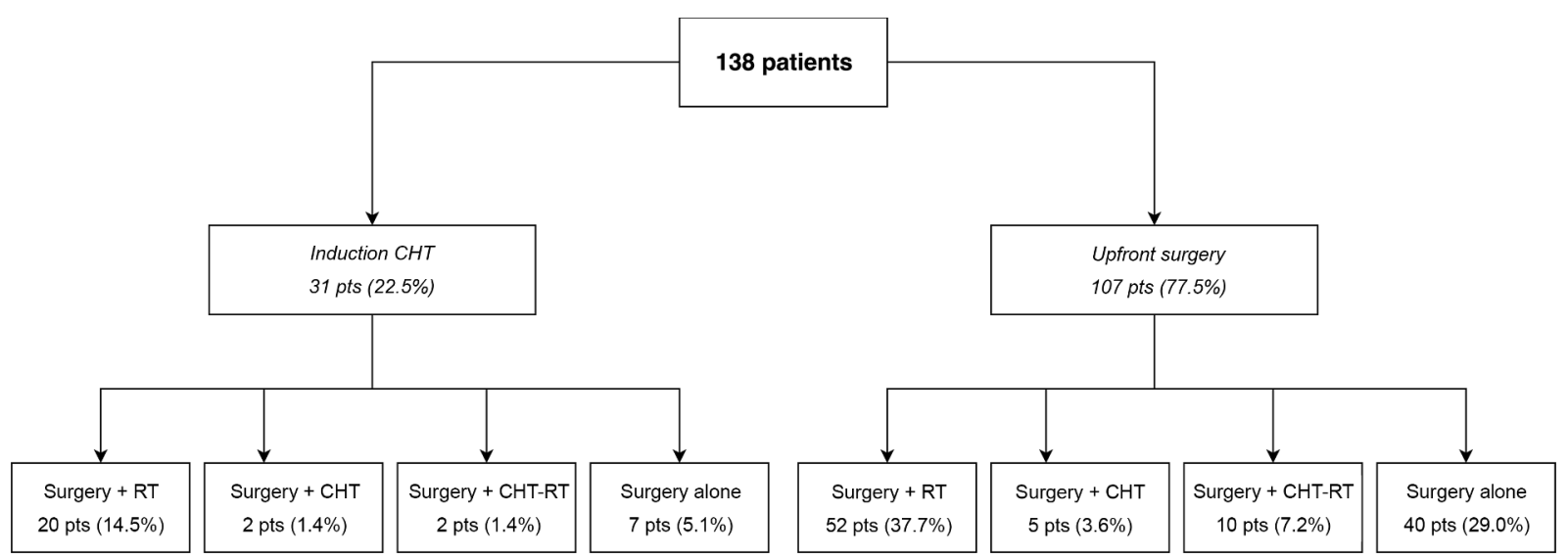

Fig. 1. Flow-chart summarizing the modalities included in the treatment schedule.

Table 1

Histology distribution - ONB, Olfactory neuroblastoma; PNET, Primitive neuroectodermal tumor; NOS, Not otherwise specified. ${ }^{\mathrm{H}}$ Classified as high-grade tumor, ${ }^{\mathrm{L}}$ classified as low-grade tumor.

\begin{tabular}{|c|c|}
\hline Variable & Distribution \\
\hline Histology & 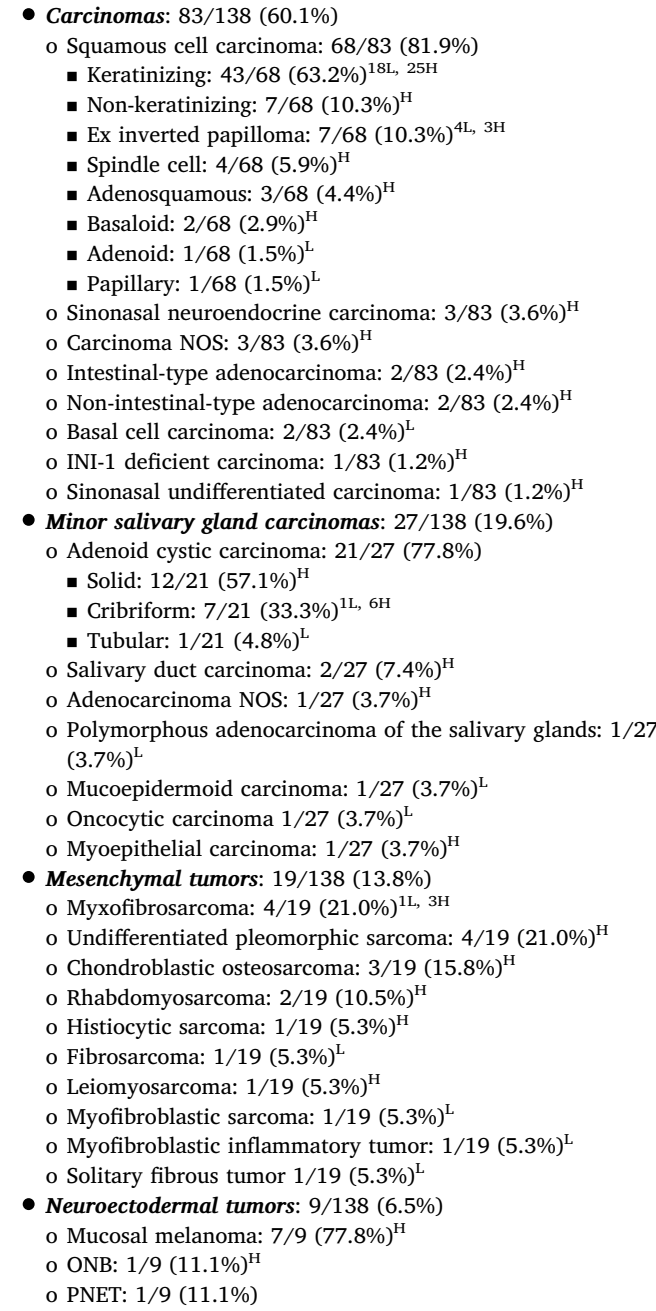 \\
\hline
\end{tabular}

the orbit in $42(30.4 \%)$ patients and a large portion of the skull base in 31 (22.5\%; anterior skull base in 10, middle skull base in 16, and both in 5 patients). Nodal invasion was uncommon, with 121 (87.5\%) cases being classified as N0 (Table 2). The rate of nodal metastasis
Table 2

Tumor characteristics.

\begin{tabular}{|c|c|}
\hline Variable & Distribution \\
\hline pT classification & $\begin{array}{l}\text { - T1: } 1 / 138(0.7 \%) \\
\text { - T2: } 10 / 138(7.2 \%) \\
\text { T3: } 20 / 138(14.4 \%) \\
\text { - T4: } 107 / 138(77.5 \%) \\
\text { o T4a: } 49 / 107(45.8 \%) \\
\text { o T4b: } 58 / 107(54.2 \%)\end{array}$ \\
\hline $\mathrm{N}$ classification & $\begin{array}{l}\text { - N0: } 121 / 138(87.7 \%) \\
\text { - N1: 5/138 (3.6\%) } \\
\text { - N2a: 2/138 (1.4\%) } \\
\text { - N2b: 5/138 (3.6\%) } \\
\text { - N3b: 5/138 (3.6\%) }\end{array}$ \\
\hline Nodal levels involved & $\begin{array}{l}\text { - Level I: 6/17 (35.3\%) } \\
\text { - Level II: } 11 / 17(64.7 \%) \\
\text { - Level III: 8/17 (47.1\%) } \\
\text { - Level IV: 2/17 (11.8\%) } \\
\text { - Level V: 3/17 (17.6\%) } \\
\text { - } \text { Level VI: 2/17 (11.8\%) }\end{array}$ \\
\hline UICC stage & $\begin{array}{l}\text { - Stage I: } 1 / 138(0.7 \%) \\
\text { - Stage II: } 10 / 138(7.2 \%) \\
\text { - Stage III: } 18 / 138(13.0 \%) \\
\text { - Stage IVA: } 50 / 138(36.2 \%) \\
\text { - Stage IVB: } 59 / 138(42.5 \%)\end{array}$ \\
\hline Perineural invasion & Present: $68 / 138(49.3 \%)$ \\
\hline Vascular invasion & Present: 43/138 (31.2\%) \\
\hline Pattern of neurovascular invasion & $\begin{array}{l}\text { - } \mathrm{P}_{0} \mathrm{~V}_{0}: 63 / 138(45.7 \%) \\
\text { - } \mathrm{P}_{1} \mathrm{~V}_{0}: 32 / 135(23.2 \%) \\
\text { - } \mathrm{P}_{0} \mathrm{~V}_{1}: 7 / 138(5.1 \%) \\
\text { - } \mathrm{P}_{1} \mathrm{~V}_{1}: 36 / 138(26.1 \%)\end{array}$ \\
\hline
\end{tabular}

progressively increased from neuroectodermal tumors $(0.0 \%)$, to mesenchymal cancers $(5.3 \%)$, non-salivary carcinomas $(12.0 \%)$, and salivary malignancies $(22.2 \%)$, without reaching statistical significance ( $\mathrm{p}=0.288$ ). Low- and high-grade maxillary malignancies had similar rate of nodal metastases $(11.1 \%$ and $12.7 \%$, respectively; $\mathrm{p}=0.798)$.

According to the final histologic examination, $71(51.8 \%)$ patients had microscopically involved margins, and 16 (11.6\%) patients had negative margins closer than $5 \mathrm{~mm}$ to the tumor. In 12/71 (16.9\%) patients with positive margins, PNI was partially or totally responsible for margin involvement. PNI and LVI were found in 68 (49.3\%) and 43 (31.2\%) tumors, respectively. In 20/68 (29.4\%) patients, PNI was identified in a tissue labelled as branch/part of a named nerve (trigeminal, vidian, oculomotor-trochlear-abducens); in the remaining cases, PNI was detected only in small nervous branches. Epineural invasion with no PNI was observed in 28 (20.3\%) patients. Intraneural invasion was found in $23(16.7 \%)$ tumors, all of which displayed also PNI. Thirty-nine $(28.3 \%)$ cancers showed tumor cells in both vascular wall and lumen, whereas only $4(2.9 \%)$ patients had a vascular wall invaded with no intraluminal cells. According to the pattern of 
Table 3

Association of grade and histology with the pattern of neurovascular invasion.

\begin{tabular}{|c|c|c|c|c|c|c|}
\hline Feature & & $\mathrm{P}_{0} \mathrm{~V}_{0}$ & $\mathrm{P}_{1} \mathrm{~V}_{0}$ & $\mathrm{P}_{0} \mathrm{~V}_{1}$ & $\mathrm{P}_{1} \mathrm{~V}_{1}$ & p-value \\
\hline \multirow[t]{2}{*}{ Grade } & Low-grade $(n=36)$ & $23(63.9 \%)$ & $8(22.2 \%)$ & $2(5.6 \%)$ & $3(8.3 \%)$ & 0.014 \\
\hline & High-grade $(n=102)$ & $40(39.2 \%)$ & $24(23.5 \%)$ & $5(4.9 \%)$ & $33(32.4 \%)$ & \\
\hline \multirow[t]{4}{*}{ Histology } & Carcinomas $(\mathrm{n}=83)$ & $41(49.4 \%)$ & $16(19.3 \%)$ & $5(6.0 \%)$ & $21(25.3 \%)$ & $<0.0001$ \\
\hline & Mesenchymal tumors $(\mathrm{n}=19)$ & $14(73.7 \%)$ & $2(10.5 \%)$ & $1(5.3 \%)$ & $2(10.5 \%)$ & \\
\hline & Neuroectodermal tumors $(n=9)$ & $6(66.7 \%)$ & $2(22.2 \%)$ & $1(11.1 \%)$ & $0(0.0 \%)$ & \\
\hline & Salivary tumors $(\mathrm{n}=27)$ & $2(7.4 \%)$ & $12(44.4 \%)$ & $0(0.0 \%)$ & $13(48.1 \%)$ & \\
\hline
\end{tabular}

neurovascular invasion: $63(45.7 \%)$ cases were classified as $\mathrm{P}_{0} \mathrm{~V}_{0}, 32$ (23.2\%) as $\mathrm{P}_{1} \mathrm{~V}_{0}, 7(5.1 \%)$ as $\mathrm{P}_{0} \mathrm{~V}_{1}$, and $36(26.1 \%)$ as $\mathrm{P}_{1} \mathrm{~V}_{1}$ (Table 2).

The treatment schedules included neoadjuvant chemotherapy in 31 $(22.5 \%)$ patients, 22 of which $(15.9 \%)$ received surgery and adjuvant radiation (combined with chemotherapy in 2 [1.4\%] patients), 7 (5.1\%) surgery alone, and $2(1.4 \%)$ surgery followed by adjuvant chemotherapy. Sixty-two patients (44.9\%) were treated with upfront surgery followed by adjuvant radiation therapy (combined with chemotherapy in 10 [7.2\%] patients), $40(39.0 \%)$ received surgery alone, and $5(3.6 \%)$ surgery with adjuvant chemotherapy (Fig. 1).

Pattern of neurovascular invasion versus histology, grade, margin status, and topographic extent

Histological category was significantly associated with the pattern of neurovascular invasion, with $\mathrm{P}_{1} \mathrm{~V}_{0}$ and $\mathrm{P}_{1} \mathrm{~V}_{1}$ tumors being more represented in non-salivary carcinomas and salivary tumors $(\mathrm{p}=0.0002)$ (Table 3). Similarly, grade was associated with the pattern of neurovascular invasion, as the high-grade group showed a higher rate of $P_{1} V_{0}$ and $\mathrm{P}_{1} \mathrm{~V}_{1}$ cancers $(\mathrm{p}=0.024)($ Table 3$) . \mathrm{P}_{0} \mathrm{~V}_{1}$ and $\mathrm{P}_{1} \mathrm{~V}_{1}$ cancers had a higher rate of involved margins ( $85.7 \%$ and $72.2 \%$, respectively) as compared to $\mathrm{P}_{0} \mathrm{~V}_{0}$ and $\mathrm{P}_{1} \mathrm{~V}_{0}$ tumors $(41.3 \%$ and $40.6 \%$, respectively; $\mathrm{p}=0.003$ ).

The rate of involvement of anatomical structures listed in Supplementary Table 1 was significantly associated with the pattern of neurovascular invasion of the tumor, especially for superior and posterior structures (Table 4, Supplementary Table 2, Supplementary Figs. 1-4). At sub-analysis, PNI had an isolated effect on involvement of superior, posterior, and medial structures, whereas LVI was associated with a higher rate of involvement of inferior structures, yet not reaching statistical significance (Supplementary Table 3). Nodal metastases were more frequently found in $\mathrm{P}_{0} \mathrm{~V}_{1}(28.6 \%)$ and $\mathrm{P}_{1} \mathrm{~V}_{1}(22.2 \%)$ tumors (Table 4, Supplementary Table 2). Consistently, the probability of having nodal metastasis was significantly associated with the presence of LVI (relative risk: 3.16, $\mathrm{p}=0.009$ ) while it was independent of PNI (relative risk: $1.89, \mathrm{p}=0.174$ ).

\section{Oncologic outcomes}

Mean duration of follow-up was 38.9 months. Three- and 5-year survival estimates were $60.7 \%$ and $52.4 \%$ for OS, $62.6 \%$ and $57.2 \%$ for DSS, $47.5 \%$ and $41.0 \%$ for RFS, $63.5 \%$ and $56.8 \%$ for LRFS, $81.8 \%$ and $81.8 \%$ for RRFS, and $76.4 \%$ and $69.7 \%$ for DRFS. At univariate analysis, high pT category (pT4), nodal metastasis, PNI, LVI, and pattern of neurovascular spread had a significant negative impact on the majority of outcomes (Table 5). Age at surgery, gender, presentation, histological category, grading, margin status, and treatment schedule were not significantly associated with any outcome. The pattern of neurovascular spread was excluded from the multivariate analysis as it would have implied a redundancy of information with regards to PNI and LVI considered separately. Nodal metastasis and PNI were independent prognostic factors for OS, DSS, and RFS (Table 5, Fig. 2). The pattern of recurrence was poorly predictable by the multivariate model, as no factor was significantly independent when analyzing LRFS, RRFS, and DRFS (Table 5).

\section{Discussion}

The present study analyzed 138 patients treated for maxillary sinus cancer over an 18-year period in a single referral center. An important finding is that most maxillary cancers were diagnosed at a locally very advanced stage, with $42.0 \%$ of tumors classified as pT4b. This is likely caused by the silent and non-specific symptoms that these tumors give rise to during initial growth. Another factor related to advanced-stage presentation is that more than half of cancers grow along nerves, vessels, or both, which substantially guide the local extension of tumor. Specifically, $\mathrm{P}_{1} \mathrm{~V}_{0}$ and $\mathrm{P}_{1} \mathrm{~V}_{1}$ tumors showed a propensity to invade superior, medial, and posterior structures, while the presence of LVI (i.e. $\mathrm{P}_{0} \mathrm{~V}_{1}$ and $\mathrm{P}_{1} \mathrm{~V}_{1}$ tumors) was associated with a higher rate of infiltration of inferior structures and nodal metastasis. This translated into a significant association between pattern of neurovascular invasion and prognosis, with special reference to OS, DSS, RFS, LRFS, and DRFS. PNI and nodal involvement were also confirmed as independent negative prognosticators at multivariate analysis, as observed in other studies $[30,33,43-45]$. Notably, nodal involvement was most frequently found in salivary malignancies independently of the grade.

The descriptive breakdown of the present series reflects several historical and emerging issues related to maxillary cancer. Beside the well-known tendency for advanced stage presentation (Table 2), the histological diversity of tumors arising from the maxilla was well represented in this series, with $39.9 \%$ of cancers classified as non-SCC malignancies (Table 1). Minor salivary gland carcinomas, mesenchymal malignancies, and neuroectodermal tumors were mainly constituted of ACC, soft tissue sarcomas, and mucosal melanoma, respectively. The heterogeneity of the multidisciplinary treatment schedule, which resulted in 8 clusters of modalities (Fig. 1), reflects the effort of tailoring therapy according to the biological behavior of the tumor. This concept is soundly settling into the management philosophy of sinonasal cancer. Most importantly, $22.5 \%$ of patients underwent induction chemotherapy, which is progressively and proficiently used in management of cancers of the sinonasal tract $[18,46,47]$, with special reference to the potential of reliably guiding definitive treatment [20] and increasing the probability of functional eye preservation [21]. In the present retrospective study, induction chemotherapy did not provide a survival benefit at univariate analysis. However, this result is deeply biased by the inclusion of tumors with diverse histology and presentation. Of note, a number of patients included in this analysis were recruited in SINTART1, which is a phase 2 trial prospectively assessing the potential benefit of multidisciplinary management including induction chemotherapy with histology-driven regimen and state-of-theart radiation therapy in patients affected by operable sinonasal cancers (Clinicaltrials.gov identifier: NCT02099175). The trial will provide more information on the role of induction chemotherapy in selected sinonasal malignancies (poorly differentiated SCC, sinonasal undifferentiated carcinoma, sinonasal neuroendocrine carcinoma, and adenocarcinoma), and the recruitment phase has been recently closed. In the present series, a substantial portion (39.0\%) of patients were treated with surgery alone. This cluster includes both early (T1-T2, N0 tumors) and recurrent cancers that were previously irradiated, the latter hardly being candidates for adjuvant re-irradiation. Interestingly, recurrent cancers were not associated with unfavorable prognosis, thus 
Table 4

Association between local extension, expressed as frequency of structures involvement, and pattern of neurovascular invasion.

\begin{tabular}{|c|c|c|c|c|c|c|}
\hline Topography & Structure & $\mathrm{P}_{0} \mathrm{~V}_{0}$ & $\mathrm{P}_{0} \mathrm{~V}_{1}$ & $\mathrm{P}_{1} \mathrm{~V}_{0}$ & $\mathrm{P}_{1} \mathrm{~V}_{1}$ & $\mathrm{p}$-value \\
\hline \multirow[t]{7}{*}{ Superior structures } & Overall (superior) & $50.8 \%$ & $42.9 \%$ & $81.3 \%$ & $88.9 \%$ & $<0.0001$ \\
\hline & Infraorbital nerve & $31.7 \%$ & $42.9 \%$ & $56.3 \%$ & $69.4 \%$ & 0.002 \\
\hline & Inferior orbital fissure & $15.9 \%$ & $14.3 \%$ & $43.8 \%$ & $61.1 \%$ & $<0.0001$ \\
\hline & Orbital floor/periorbit & $44.4 \%$ & $28.6 \%$ & $75.0 \%$ & $66.7 \%$ & 0.007 \\
\hline & Intraorbital structures & $20.6 \%$ & $28.6 \%$ & $43.8 \%$ & $41.7 \%$ & 0.049 \\
\hline & Superior orbital fissure & $1.6 \%$ & $0.0 \%$ & $21.9 \%$ & $30.6 \%$ & $<0.0001$ \\
\hline & Frontal sinus & $6.3 \%$ & $0.0 \%$ & $12.5 \%$ & $11.1 \%$ & 0.653 \\
\hline \multirow[t]{5}{*}{ Inferior structures } & Overall (inferior) & $65.1 \%$ & $85.7 \%$ & $68.8 \%$ & $91.7 \%$ & 0.015 \\
\hline & Hard palate & $52.4 \%$ & $71.4 \%$ & $50.0 \%$ & $86.1 \%$ & 0.002 \\
\hline & Alveolar process & $58.7 \%$ & $71.4 \%$ & $59.4 \%$ & $75.0 \%$ & 0.372 \\
\hline & Soft palate & $6.3 \%$ & $0.0 \%$ & $25.0 \%$ & $13.9 \%$ & 0.058 \\
\hline & Buccinator muscle & $19.0 \%$ & $14.3 \%$ & $18.8 \%$ & $22.2 \%$ & 0.970 \\
\hline \multirow{4}{*}{ Medial structures } & Overall (medial) & $54.0 \%$ & $42.9 \%$ & $78.1 \%$ & $83.3 \%$ & 0.004 \\
\hline & Ethmoid & $34.9 \%$ & $28.6 \%$ & $56.3 \%$ & $69.4 \%$ & 0.004 \\
\hline & Nasolacrimal duct & $36.5 \%$ & $14.3 \%$ & $53.1 \%$ & $52.8 \%$ & 0.114 \\
\hline & Nasal septum & $23.8 \%$ & $42.9 \%$ & $46.9 \%$ & $44.4 \%$ & 0.060 \\
\hline \multirow[t]{4}{*}{ Lateral structures } & Overall (lateral) & $69.8 \%$ & $57.1 \%$ & $75.0 \%$ & $77.8 \%$ & 0.622 \\
\hline & Infratemporal fat & $38.1 \%$ & $28.6 \%$ & $50.0 \%$ & $63.9 \%$ & 0.067 \\
\hline & Temporal/masseteric muscle & $19.0 \%$ & $28.6 \%$ & $28.1 \%$ & $36.1 \%$ & 0.287 \\
\hline & Zygomatic bone & $50.8 \%$ & $57.1 \%$ & $65.6 \%$ & $52.8 \%$ & 0.583 \\
\hline Anterior structures & Premaxillary tissues & $47.6 \%$ & $57.1 \%$ & $68.8 \%$ & $58.3 \%$ & 0.261 \\
\hline \multirow[t]{13}{*}{ Posterior structures } & Overall (posterior) & $47.6 \%$ & $42.9 \%$ & $75.0 \%$ & $97.2 \%$ & $<0.0001$ \\
\hline & Pterygopalatine fossa & $30.2 \%$ & $28.6 \%$ & $62.5 \%$ & $91.7 \%$ & $<0.0001$ \\
\hline & Pterygoid plates & $25.4 \%$ & $14.3 \%$ & $43.8 \%$ & $86.1 \%$ & $<0.0001$ \\
\hline & Pterygoid muscles & $23.8 \%$ & $28.6 \%$ & $46.9 \%$ & $66.7 \%$ & 0.0002 \\
\hline & Branches of V3 & $9.5 \%$ & $0.0 \%$ & $28.1 \%$ & $36.1 \%$ & 0.004 \\
\hline & Foramen rotondum & $3.2 \%$ & $14.3 \%$ & $28.1 \%$ & $58.3 \%$ & $<0.0001$ \\
\hline & Foramen ovale & $6.3 \%$ & $0.0 \%$ & $18.8 \%$ & $25.0 \%$ & 0.037 \\
\hline & Vidian nerve/canal & $7.9 \%$ & $14.3 \%$ & $43.8 \%$ & $52.8 \%$ & $<0.0001$ \\
\hline & Meckel's cave & $0.0 \%$ & $0.0 \%$ & $9.4 \%$ & $13.9 \%$ & 0.012 \\
\hline & Cavernous sinus & $0.0 \%$ & $0.0 \%$ & $18.8 \%$ & $19.4 \%$ & 0.0004 \\
\hline & Nasopharynx & $14.3 \%$ & $0.0 \%$ & $40.6 \%$ & $55.6 \%$ & $<0.0001$ \\
\hline & Sphenoid & $15.9 \%$ & $0.0 \%$ & $37.5 \%$ & $58.3 \%$ & $<0.0001$ \\
\hline & Lateral middle skull base & $9.5 \%$ & $0.0 \%$ & $31.3 \%$ & $36.1 \%$ & 0.003 \\
\hline Nodal metastases & & $6.4 \%$ & $28.6 \%$ & $9.4 \%$ & $22.2 \%$ & 0.051 \\
\hline
\end{tabular}

suggesting that tumor presentation is likely eclipsed by other prognostic factors, when salvage surgery is feasible.

Almost half of resections had involved margins, which in turn did not imply a significant worsening of prognosis. The absence of a measurable impact on outcomes, which contrasts with other published series $[48,49]$, might be caused by histological heterogeneity and other confounders such as the systematic use of defect-driven frozen-sections and, when indicated, additional specimens. In fact, when uninvolved additional specimens were not clearly orientable with respect to a positive margin on the main specimen, the margin status was considered as involved on a precautional basis, thus possibly leading to overestimation of margin infiltration. Bristol et al. found that margin status was not significantly associated with prognosis at univariate analysis, but was independently associated with survival when inserted in a multivariate model, thus confirming that clear margins should be pursued whenever possible [17]. In the present study, the number of events did not allow the inclusion in multivariate analysis of variables not showing significance at univariate analysis [50]. In agreement with another study [17], a margin $<5 \mathrm{~mm}$ did not translate into poorer survival. This finding suggests that the general definition of "close margins" used for oral cancer may not apply to sinonasal malignancies. Of note, 41 of $71(57.7 \%)$ patients with positive margins underwent adjuvant radiotherapy with state-of-the-art methodology including intensity-modulated radiation therapy, high dose (i.e. $66 \mathrm{~Gy}$ ) in high-risk volumes, and concomitant chemotherapy, whenever indicated according to histologic features and the patient's conditions. Among these patients, 9 of $20(45.0 \%)$ who had previously received radiation underwent re-irradiation. This multidisciplinary approach might have mitigated the negative prognostic effect of margin involvement. The non-negligible rate of patients not receiving adjuvant treatment despite margin involvement $(30 / 71,42.3 \%)$ was mostly related to the patient's refusal to undergo radiotherapy or to ineligibility to radiation within the 2-month postoperative window due to comorbidities and/or complications. The fact that this subgroup was not associated with worse survival should be interpreted cautiously, as a number of factors might have biased this result (e.g. histological heterogeneity with different event-free latency, overestimation of positive margins). Overall, it can be concluded that control of surgical margins in maxillary cancer is an unmet challenge and should attract the attention of researchers in HN oncology.

In the present series, 5-year OS and RFS were $52.4 \%$ and $41.0 \%$, respectively, with the majority of patients experiencing local and distant recurrences. On one hand, these results imply a large room for improvement, while on the other hand, when contextualizing these data within a timeline of maxillary cancer oncologic outcomes, an encouraging trend can be seen. As already shown by Dulguerov et al. [51], 5 -year OS of patients treated for maxillary cancer progressively increased from $20-35 \%$ in $60-70$ ies [52-55], to $30-47 \%$ in the $80-90$ ies [24-26], up to $58-71 \%$ in the last 2 decades [9,56]. However, a prognostic model based on the Surveillance Epidemiology and End Results (SEER) database reports a 5 -year OS as low as $39.7 \%$ in 668 patients treated between 2004 and 2013 [27]. Moreover, it is worth highlighting that the concept of "resectability" is also evolving, as very advanced sinonasal cancers (i.e. T4b tumors), which represented a considerable portion of the present series $(42.0 \%)$, have been considered suitable for upfront surgery only in recent times [57].

Although PNI and LVI have been already considered distinctly in sinonasal cancers $[37,38]$, to the best of our knowledge this is the first study analyzing the two modalities of growth simultaneously by defining the pattern of neurovascular invasion, which was associated with all oncologic outcomes except RRFS.

Histology and grade were significantly associated with the pattern 


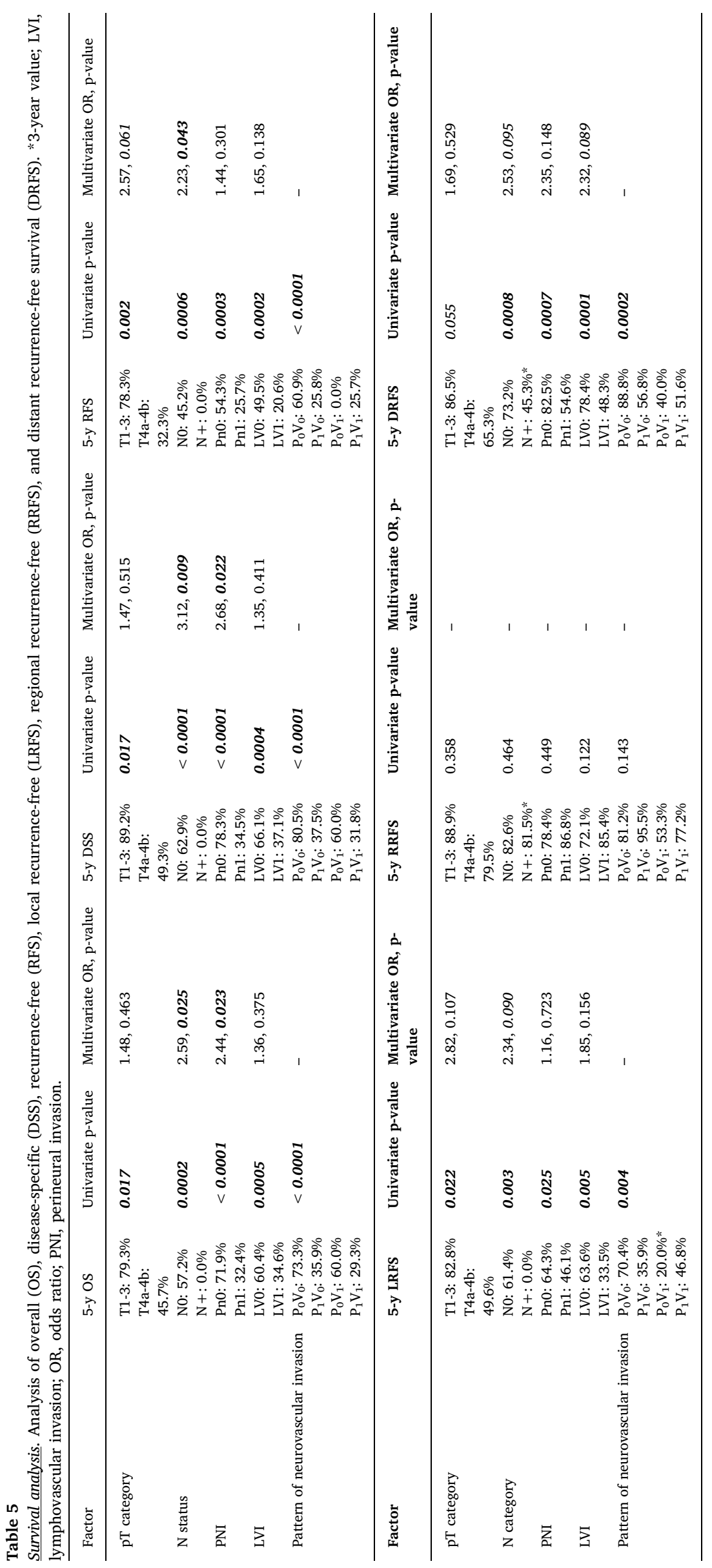



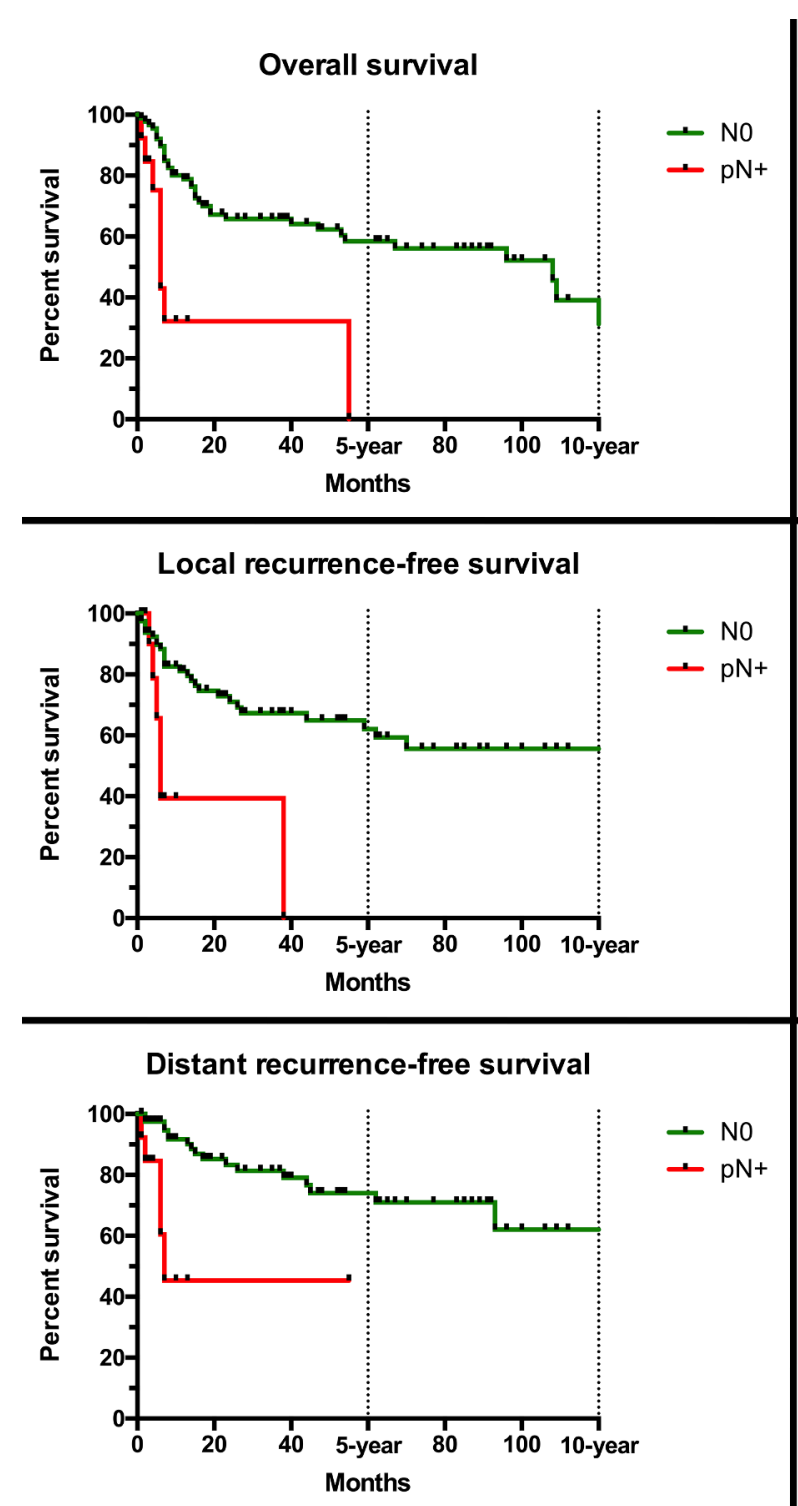

Overall survival

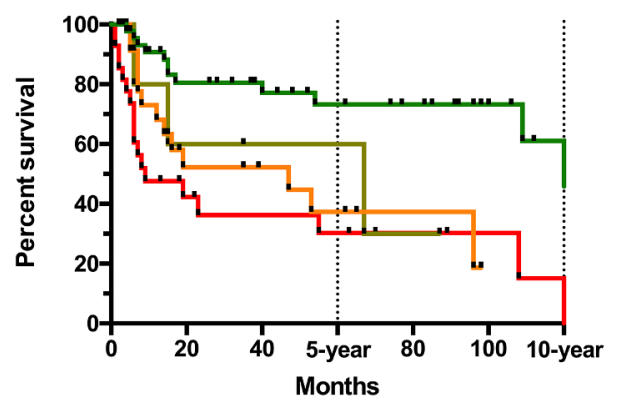

- POVO

- P1V0

- POV1

$+\mathrm{P} 1 \mathrm{~V} 1$

+ P1V1
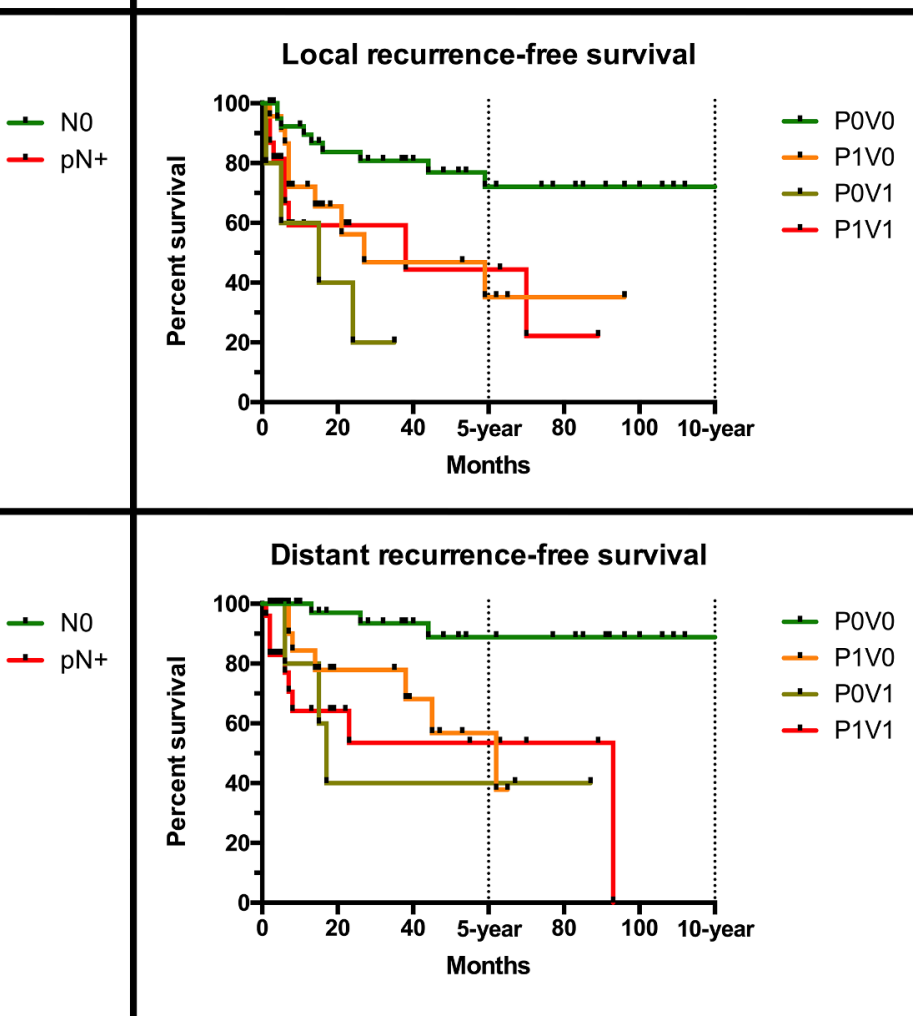

Distant recurrence-free survival

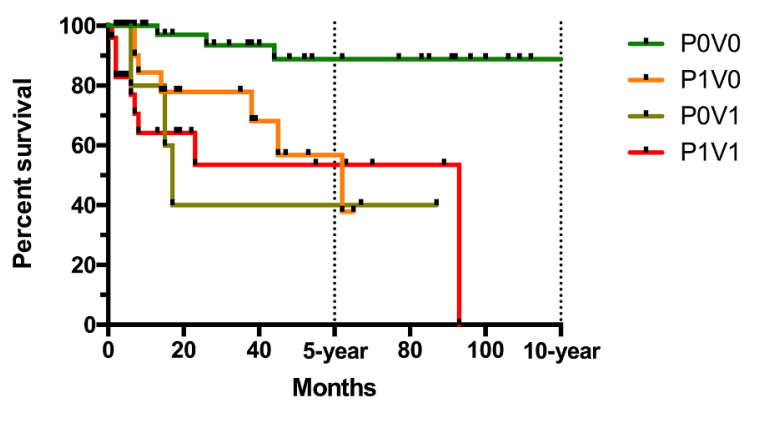

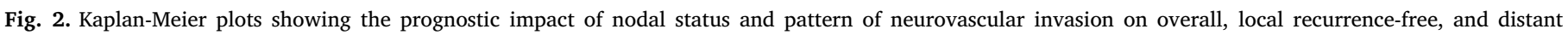
recurrence-free survival. Compare with Table 5 for p-values.

of neurovascular invasion. This finding suggests that PNI and LVI represent a gain of function that is acquired more frequently by highgrade tumors, with special reference to salivary and non-salivary carcinomas, while mesenchymal and neuroectodermal cancers rarely display these features [38]. Moreover, analysis of the pattern of neurovascular invasion allowed the observation that LVI is rarely found alone, with only 7 of $43(16.3 \%)$ cancers with LVI classified as $\mathrm{P}_{0} \mathrm{~V}_{1}$ (Table 2). The fact that most tumors with LVI also displayed PNI could be related to some overlap between the molecular mechanisms behind these histologic modalities of growth. In fact, phenomena such as macrophage recruitment and overexpression of metalloproteinases are observed in both PNI and LVI, while other biological mechanisms are specific for only one type of invasion (e.g. overexpression of CCR2 and CXCR5 for PNI and CCR7 for LVI) [58-60].

The most original finding of the present study is that the pattern of neurovascular invasion significantly affected the invasion of anatomical structures neighboring the maxillary sinus with an eccentric topography. Apart from ACC (21 patients), which is well known to display PNI and possibly LVI, it is of note that most tumors with $\mathrm{P}_{1} \mathrm{~V}_{0}, \mathrm{P}_{0} \mathrm{~V}_{1}$, and $\mathrm{P}_{1} \mathrm{~V}_{1}$ pattern were non-salivary carcinomas $(16,5$, and 21 patients, respectively). $\mathrm{P}_{1} \mathrm{~V}_{0}$ and $\mathrm{P}_{1} \mathrm{~V}_{1}$ malignancies tended to invade superior, medial, and posterior structures more frequently compared to other tumors (Supplementary Figs. 2 and 4), while $\mathrm{P}_{0} \mathrm{~V}_{1}$ and $\mathrm{P}_{1} \mathrm{~V}_{1}$ tumors showed a propensity towards invasion of the hard palate and nodal metastasis (Supplementary Figs. 3 and 4). This observation is in line with other studies that suggested that there might be correlation between neurovascular invasion, tumor origin, and local extension: Singh et al. showed that HN ACC has a propensity to grow towards the orbit and skull base by following the trigeminal-facial network [61]; MartinsAndrade et al. reported that the risk of nodal metastasis in HN ACCs was more than doubled when LVI was detected [37]; Liu et al. found that PNI and LVI were heterogeneously frequent in different oral SCCs depending upon the subsite of origin [35]. The concept of correlation between pattern of neurovascular invasion and propensity of the tumor to invade specific anatomical area could be of value to physicians who need to delineate a boundary of treatment (e.g. target contouring for radiation).

The present study has some limitations that cannot be neglected: first, it is based on a retrospective analysis of patients over an 18-year period; second, the total number of events (48 patients dead of any 
cause) limited multivariate analysis to include 4 factors; third, the variety of histologies forced us to a simplistic classification of tumors in 4 categories.

\section{Conclusion}

The present study suggests that maxillary cancer represents an open issue in HN oncology. Pattern of neurovascular invasion affects the local spread of tumor and physicians delivering locoregional treatment should be aware of this finding. Achieving clear margins is a challenge. Since PNI decreases survival independently of other variables, it appears to be a logical target for biological and pharmaceutical research aimed at improving efficacy of treatment in patients with sinonasal cancer. Nodal metastasis is favored by LVI and has a negative impact on prognosis, findings that are even more relevant compared to other $\mathrm{HN}$ cancers.

\section{Appendix A. Supplementary data}

Supplementary data to this article can be found online at https:// doi.org/10.1016/j.oraloncology.2020.104672.

\section{References}

[1] Bhattacharyya N. Survival and staging characteristics for non-squamous cell malignancies of the maxillary sinus. Arch Otolaryngol - Head Neck Surg 2003;129(3):334-7. https://doi.org/10.1001/archotol.129.3.334.

[2] Bhattacharyya N. Factors affecting survival in maxillary sinus cancer. J Oral Maxillofac Surg 2003;61(9):1016-21. https://doi.org/10.1016/s0278-2391(03) 00313-6.

[3] Shah JP, Patel SG, Singh B, Wong RJ. Jatin Shah's head and neck surgery and oncology. 5th ed. Elsevier; 2019.

[4] Seong SY, Hyun DW, Kim YS, et al. Treatment outcomes of sinonasal adenoid cystic carcinoma: 30 cases from a single institution. J Cranio-Maxillofacial Surg 2014;42(5). https://doi.org/10.1016/j.jcms.2013.08.002.

[5] Andrade MF, De Faria PR, Cardoso SV, et al. Adenoid cystic carcinoma of the maxillary sinus: a clinical-pathological report of 10 years of experience from a single institution. Int J Oral Maxillofac Surg 2014;43(11):1313-8. https://doi.org/10. 1016/j.ijom.2014.06.016.

[6] Trope M, Triantafillou V, Kohanski MA, et al. Adenoid cystic carcinoma of the sinonasal tract: a review of the national cancer database. Int Forum Allergy Rhinol 2019;9(4):427-34. https://doi.org/10.1002/alr.22255.

[7] Unsal AA, Chung SY, Zhou AH, Baredes S, Eloy JA. Sinonasal adenoid cystic carcinoma: a population-based analysis of 694 cases. Int Forum Allergy Rhinol 2017;7(3):312-20. https://doi.org/10.1002/alr.21875.

[8] Hayashi T, Nonaka S, Bandoh N, Kobayashi Y, Imada M, Harabuchi Y. Treatment outcome of maxillary sinus squamous cell carcinoma. Cancer 2001;92(6):1495-503. https://doi.org/10.1002/1097-0142(20010915)92:6<1495::aid-cncr1474 > 3.0. co;2-p.

[9] Kondo A, Kurose M, Obata K, et al. A clinical study of maxillary sinus squamous cell carcinoma. Adv Otorhinolaryngol 2016;77:83-7. https://doi.org/10.1159/ 000441879.

[10] Santos MRM, Servato JPS, Cardoso SV, et al. Squamous cell carcinoma at maxillary sinus: clinicopathologic data in a single brazilian institution with review of literature. Int J Clin Exp Pathol 2014;7(12):8823-32.

[11] López F, Lund VJ, Suárez C, et al. The impact of histologic phenotype in the treatment of sinonasal cancer. Adv Ther 2017;34(10):2181-98. https://doi.org/10. 1007/s12325-017-0605-9.

[12] Castelnuovo P, Turri-Zanoni M, Battaglia P, Antognoni P, Bossi P, Locatelli D. Sinonasal malignancies of anterior skull base: histology-driven treatment strategies. Otolaryngol Clin North Am 2016;49(1):183-200. https://doi.org/10.1016/j.otc. 2015.09.012.

[13] Choi EC, Choi Y-S, Kim C-H, et al. Surgical outcome of radical maxillectomy in advanced maxillary sinus cancers. Yonsei Med J 2004;45(4):621-8.

[14] Deganello A, Ferrari M, Paderno A, et al. Endoscopic-assisted maxillectomy: operative technique and control of surgical margins. Oral Oncol 2019;93:29-38. https://doi.org/10.1016/j.oraloncology.2019.04.002.

[15] Ferrari M, Daly MJ, Douglas CM, et al. Navigation-guided osteotomies improve margin delineation in tumors involving the sinonasal area: a preclinical study. Oral Oncol 2019;99. https://doi.org/10.1016/j.oraloncology.2019.104463.

[16] Zaharia M, Salem LE, Travezan R, et al. Postoperative radiotherapy in the management of cancer of the maxillary sinus. Int J Radiat Oncol Biol Phys 1989;17(5):967-71. https://doi.org/10.1016/0360-3016(89)90143-0.

[17] Bristol IJ, Ahamad A, Garden AS, et al. Postoperative radiotherapy for maxillary sinus cancer: long-term outcomes and toxicities of treatment. Int J Radiat Oncol Biol Phys 2007;68(3):719-30. https://doi.org/10.1016/j.ijrobp.2007.01.032.

[18] Hanna EY, Cardenas AD, DeMonte F, et al. Induction chemotherapy for advanced squamous cell carcinoma of the paranasal sinuses. Arch Otolaryngol - Head Neck
Surg 2011;137(1):78-81. https://doi.org/10.1001/archoto.2010.231.

[19] Turri-Zanoni M, Lambertoni A, Margherini S, et al. Multidisciplinary treatment algorithm for the management of sinonasal cancers with orbital invasion: a retrospective study. Head Neck 2019;41(8):2777-88. https://doi.org/10.1002/hed. 25759.

[20] Amit M, Abdelmeguid AS, Watcherporn T, et al. Induction chemotherapy response as a guide for treatment optimization in sinonasal undifferentiated carcinoma. J Clin Oncol 2019;37(6):504-12. https://doi.org/10.1200/JCO.18.00353.

[21] Khoury T, Jang D, Carrau R, Ready N, Barak I, Hachem RA. Role of induction chemotherapy in sinonasal malignancies: a systematic review. Int Forum Allergy Rhinol 2019;9(2):212-9. https://doi.org/10.1002/alr.22229.

[22] Chera BS, Malyapa R, Louis D, et al. Proton therapy for maxillary sinus carcinoma. Am J Clin Oncol Cancer Clin Trials 2009;32(3):296-303. https://doi.org/10.1097/ COC.0b013e318187132a.

[23] Nakamura T, Azami Y, Ono T, et al. Preliminary results of proton beam therapy combined with weekly cisplatin intra-arterial infusion via a superficial temporal artery for treatment of maxillary sinus carcinoma. Jpn J Clin Oncol 2016;46(1):46-50. https://doi.org/10.1093/jjco/hyv160.

[24] Giri SP, Reddy EK, Gemer LS, Krishnan L, Smalley SR, Evans RG. Management of advanced squamous cell carcinomas of the maxillary sinus. Cancer 1992;69(3):657-61. https://doi.org/10.1002/1097-0142(19920201) $69: 3<657:$ :aid-cncr2820690310 > 3.0.co;2-7.

[25] Wu X, Tang P, Oi Y. Management of the orbital contents in radical surgery for squamous cell carcinoma of the maxillary sinus. Chin Med J (Engl) 1995;108(2):123-5.

[26] Paulino AC, Marks JE, Bricker P, Melian E, Reddy SP, Emami B. Results of treatment of patients with maxillary sinus carcinoma. Cancer 1998;83(3):457-65.

[27] Shen W, Sakamoto N, Yang L. Prognostic models and nomograms for predicting survival of patients with maxillary sinus carcinomas. Int Forum Allergy Rhinol 2017;7(7):741-8. https://doi.org/10.1002/alr.21950.

[28] Nazar G, Rodrigo JP, Llorente JL, Baragaño L, Suárez C. Prognostic factors of maxillary sinus malignancies. Am J Rhinol 2014;18(4):233-8.

[29] Carrillo JF, Güemes A, Ramírez-Ortega MC, Oñate-Ocaña LF. Prognostic factors in maxillary sinus and nasal cavity carcinoma. Eur J Surg Oncol 2005;31(10):1206-12. https://doi.org/10.1016/j.ejso.2005.04.001.

[30] Kano S, Hayashi R, Homma A, et al. Effect of local extension sites on survival in locally advanced maxillary sinus cancer. Head Neck 2014;36(11):1567-72. https:// doi.org/10.1002/hed.23483.

[31] Chen AM, Bucci MK, Weinberg V, et al. Adenoid cystic carcinoma of the head and neck treated by surgery with or without postoperative radiation therapy: prognostic features of recurrence. Int J Radiat Oncol Biol Phys 2006;66(1):152-9. https://doi. org/10.1016/j.ijrobp.2006.04.014.

[32] Volpi L, Bignami M, Lepera D, et al. Endoscopic endonasal resection of adenoid cystic carcinoma of the sinonasal tract and skull base. Laryngoscope 2019;129(5):1071-7. https://doi.org/10.1002/lary.27485.

[33] Garden AS, Weber RS, Morrison WH, Ang KK, Peters LJ. The influence of positive margins and nerve invasion in adenoid cystic carcinoma of the head and neck treated with surgery and radiation. Int $\mathrm{J}$ Radiat Oncol Biol Phys 1995;32(3):619-26. https://doi.org/10.1016/0360-3016(95)00122-F.

[34] Michel J, Fakhry N, Santini L, Mancini J, Giovanni A, Dessi P. Sinonasal adenoid cystic carcinomas: clinical outcomes and predictive factors. Int J Oral Maxillofac Surg 2013;42(2):153-7. https://doi.org/10.1016/j.ijom.2012.11.007.

[35] Liu SA, Wang CC, Jiang RS, Lee FY, Lin WJ, Lin JC. Pathological features and their prognostic impacts on oral cavity cancer patients among different subsites - a singe institute's experience in Taiwan. Sci Rep 2017;7(1):7451. https://doi.org/10.1038/ s41598-017-08022-w.

[36] Adel M, Kao HK, Hsu CL, et al. Evaluation of lymphatic and vascular invasion in relation to clinicopathological factors and treatment outcome in oral cavity squamous cell carcinoma. Medicine (Baltimore) 2015;94(43):e1510. https://doi.org/10. 1097/MD.0000000000001510.

[37] Martins-Andrade B, Dos Santos Costa SF, Sant'ana MSP, et al. Prognostic importance of the lymphovascular invasion in head and neck adenoid cystic carcinoma: a systematic review and meta-analysis. Oral Oncol 2019;93:52-8. https:// doi.org/10.1016/j.oraloncology.2019.04.014.

[38] Gil Z, Carlson DL, Gupta A, et al. Patterns and incidence of neural invasion in patients with cancers of the paranasal sinuses. Arch Otolaryngol - Head Neck Surg 2009;135(2):173-9. https://doi.org/10.1001/archoto.2008.525.

[39] El-Naggar AK, Chan JKC, Rubin Grandis J, Takata T, Slootweg PJ. WHO classification of head and neck tumours. 4th ed. Lyon: International Agency for Research on Cancer; 2017.

[40] Brierley JD, Gospodarowicz MK, Wittekind C. TNM classification of malignant tumours. Wiley-Blackwell; 2017.

[41] Brown IS. Pathology of perineural spread. J Neurol Surgery Part B Skull Base 2016;77(2):124-30. https://doi.org/10.1055/s-0036-1571837.

[42] Van Weert S, Van Der Waal I, Witte BI, René Leemans C, Bloemena E. Histopathological grading of adenoid cystic carcinoma of the head and neck: analysis of currently used grading systems and proposal for a simplified grading scheme. Oral Oncol 2015;51(1):71-6. https://doi.org/10.1016/j.oraloncology. 2014.10.007.

[43] Le QT, Birdwell S, Terris DJ, et al. Postoperative irradiation of minor salivary gland malignancies of the head and neck. Radiother Oncol 1999;52(2):165-71. https:// doi.org/10.1016/S0167-8140(99)00084-5.

[44] Dubal PM, Bhojwani A, Patel TD, Zuckerman O, Baredes S, Liu JK, et al. Squamous cell carcinoma of the maxillary sinus: a population-based analysis: Maxillary Sinus Squamous Cell Carcinoma. The Laryngoscope 2016;126(2):399-404. https://doi. org/10.1002/lary.v126.210.1002/lary.25601. 
[45] Fordice J, Kershaw C, El-Naggar A, Goepfert H. Adenoid cystic carcinoma of the head and neck: predictors of morbidity and mortality. Arch Otolaryngol - Head Neck Surg 1999;125(2):149-52. https://doi.org/10.1001/archotol.125.2.149.

[46] Kovács AF, Eberlein K, Hülsmann T. Organ preservation treatment using TPF - a pilot study in patients with advanced primary and recurrent cancer of the oral cavity and the maxillary sinus. Oral Maxillofac Surg 2009;13(2):87-93. https://doi. org/10.1007/s10006-009-0159-3.

[47] Bossi P, Saba NF, Vermorken JB, et al. The role of systemic therapy in the management of sinonasal cancer: a critical review. Cancer Treat Rev 2015;41(10):836-43. https://doi.org/10.1016/j.ctrv.2015.07.004.

[48] Ozsaran Z, Yalman D, Baltalarli B, Anacak Y, Esassolak M, Haydaroğlu A. Radiotherapy in maxillary sinus carcinomas: evaluation of 79 cases. Rhinology 2003;41(1):44-8.

[49] Nishio N, Fujimoto Y, Fujii M, et al. Craniofacial resection for T4 maxillary sinus carcinoma: managing cases with involvement of the skull base. Otolaryngol - Head Neck Surg (US) 2015;153(2):231-8. https://doi.org/10.1177/0194599815586770.

[50] Iasonos A, Schrag D, Raj GV, Panageas KS. How to build and interpret a nomogram for cancer prognosis. J Clin Oncol 2008;26(8):1364-70. https://doi.org/10.1200/ jco.2007.12.9791.

[51] Dulguerov P, Jacobsen MS, Allal AS, Lehmann W, Calcaterra T. Nasal and paranasal sinus carcinoma: are we making progress? A series of 220 patients and a systematic review. Cancer 2001;92(12):3012-29. https://doi.org/10.1002/10970142(20011215)92:12<3012::AID-CNCR10131 > 3.0.CO;2-E.

[52] Frazell EL, Lewis JS. Cancer of the nasal cavity and accessory sinuses. A report of the management of 416 patients. Cancer 1963;16:1293-301. https://doi.org/10. 1002/1097-0142(196310)16:10<1293::aid-cncr2820161010 > 3.0.co;2-4.

[53] Boone ML, Harle TS, Higholt HW, Fletcher GH. Malignant disease of the paranasal sinuses and nasal cavity. Importance of precise localization of extent of disease. Am
J Roentgenol Radium Ther Nucl Med 1968;102(3):627-36. https://doi.org/10. 2214/ajr.102.3.627.

[54] Tabb HG, Barranco SJ. Cancer of the maxillary sinus. Laryngoscope 1971;81(6):818-27. https://doi.org/10.1288/00005537-197106000-00002.

[55] Kurohara SS, Webster JH, Ellis F, Fitzgerald JP, Shedd DP, Badib AO. Role of radiation therapy and of surgery in the management of localized epidermoid carcinoma of the maxillary sinus. Am J Roentgenol Radium Ther Nucl Med 1972;114(1):35-42.

[56] Nishio N, Fujimoto Y, Hiramatsu M, et al. < Editors' Choice > Maxillary sinus carcinoma outcomes over 60 years: experience at a single institution. Nagoya J Med Sci 2018;80(1):91-8. https://doi.org/10.18999/nagjms.80.1.91.

[57] Li R, Tian S, Lin L, Liu Q, Wang S. Comparative outcome of surgical and nonsurgical therapy for T4bNOM0 sinonasal squamous cell carcinomas. Eur Arch Otorhinolaryngol 2019;276(11):3113-22. https://doi.org/10.1007/s00405-01905601-7.

[58] Aleskandarany MA, Sonbul SN, Mukherjee A, Rakha EA. Molecular mechanisms underlying lymphovascular invasion in invasive breast cancer. Pathobiology 2015;82(3-4):113-23. https://doi.org/10.1159/000433583.

[59] Marchesi F, Piemonti L, Mantovani A, Allavena P. Molecular mechanisms of perineural invasion, a forgotten pathway of dissemination and metastasis. Cytokine Growth Factor Rev 2010;21(1):77-82. https://doi.org/10.1016/j.cytogfr.2009.11. 001.

[60] Amit M, Na'Ara S, Gil Z. Mechanisms of cancer dissemination along nerves. Nat Rev Cancer 2016;16(6):399-408. https://doi.org/10.1038/nrc.2016.38.

[61] Singh FM, Mak SY, Bonington SC. Patterns of spread of head and neck adenoid cystic carcinoma. Clin Radiol 2015;70(6):644-53. https://doi.org/10.1016/j.crad. 2015.01.013. 